\title{
La economía de Tailandia
}

DOI: 10.32870/mycp.v4i12.125

Melba E. Falck*

$\mathrm{E}$ 1 Reino de Siam, hoy Tailandia, es el único país del sudeste asiático que no fue colonizado por occidente. Por su distintivo patrón de crecimiento, Tailandia ha sido considerada como "el nuevo país agroindustrializado" de la región de Asia Pacífico, dada su activa participación en los mercados alimentarios internacionales: es el mayor exportador de arroz del mundo y también líder mundial en las exportaciones de piña y atún enlatados.

Con un territorio de 500000 kilómetros cuadrados, una cuarta parte de la superficie mexicana, el crecimiento económico de Tailandia ha estado basado en los recursos naturales, sobre todo en los agrícolas, forestales y marinos. A diferencia de los otros nuevos países industrializados (NIC, por su sigla en inglés) Corea del Sur, Taiwán, Hong Kong y Singapur, la mayor parte de los 60 millones de tailandeses que habitan el Reino de Siam permanecen en el campo y la mayor concentración urbana se registra en el área metropolitana de Bangkok, la capital. El desarrollo regional desigual ha sido otra de las características del crecimiento de este país.

Por su privilegiada posición geográfica y la dotación relativa de recursos naturales de que disfruta, Tailandia ha desarrollado un patrón de integración regional, de flujo de bienes y de inversión, cada vez más intenso con sus vecinos de Laos, Myanmar y Vietnam, comparado al que sostiene con Indonesia, Malasia y Filipinas, economías estas últimas con las que tiene una menor complementariedad. La inversión extranjera procedente de Japón y de los NIC ha jugado un papel muy importante en el desarrollo reciente del país, la cual ha ido desplazando paulatinamente a la inversión procedente de Estados Unidos. Con esta última nación,

* Investigadora del Departamento de Estudios del Pacífico de la Universidad de Guadalajara.

ORCID http://orcid.org/0000-0003-4926-0594
Tailandia estableció vínculos muy estrechos a partir de la década de los cincuenta, sustentados por la política exterior de contención del comunismo que Estados Unidos mantenía en la zona.

De los cuatro países fundadores de la Asociación de Naciones del Sudeste Asiático (ASEAN-4 por su sigla en inglés); Malasia, Indonesia, Filipinas y Tailandia, esta última ha alcanzado un alto nivel de ingreso, antecedido únicamente por Malasia (cuadro 1). Al igual que sus vecinos, exceptuando a Filipinas, durante la primera mitad de los noventa, el ingreso de la pobladores de la ASEAN-4 se incrementó 5.9 por ciento anual; el mismo indicador para México en ese período fue de 0.2 por ciento (cuadro 2 ).

No obstante, en 1997 Tailandia fue la primera economía de la ASEAN-4 que se sumergió en la crisis, la cual afectando inicialmente el sector financiero, contaminó después la economía real. Hasta el año pasado Tailandia empezó a recuperarse de la crisis, después de aplicar un severo programa de reestructuración diseñado por el Banco Mundial. Con la crisis salieron a flote los problemas estructurales que había acumulado en su proceso de desarrollo.

¿Cuáles fueron los factores que propiciaron el crecimiento de este país y qué problemas estructurales se generaron en el proceso que lo condujeron a la crisis de 1997 y su lenta recuperación? Los siguientes párrafos analizan ese proceso.

\section{Desenvolvimiento económico de Tailandia $^{1}$}

No obstante de haberse librado del coloniaje occidental, Tailandia, al igual que sus vecinos del Pacífico Asiático, sufrió el control de sus finanzas impuesto por occidente a través de los "tratados desiguales". Fue hasta 1920 cuando 


\section{Cuadro 1 \\ ASEAN-4. Indicadores básicos}

1997

\begin{tabular}{|c|c|c|c|c|c|}
\hline & Unidad & Tailandia & Indonesia & Filipinas & Malasia \\
\hline Extensión territorial & Miles de $\mathrm{Km}^{2}$ & 510.90 & $1,818.00$ & 298.40 & 328.60 \\
\hline Área forestal & Porcentaje del total & 23.00 & 61.00 & 68.00 & 47.00 \\
\hline Deforestación 1990-1995 & Porcentaje anual & 1.40 & 1.00 & 3.50 & 2.40 \\
\hline Población & Millones de personas & 60.60 & 200.40 & 73.50 & 21.70 \\
\hline Crecimiento 1990-1997 & Porcentaje, promedio anual & 1.20 & 1.70 & 2.30 & 2.50 \\
\hline Esperanza de vida & Años & 69.00 & 65.00 & 68.00 & 72.00 \\
\hline Mujer en la fuerza de trabajo & Porcentaje & 46.00 & 40.00 & 37.00 & 43.00 \\
\hline \multicolumn{6}{|l|}{ Economía } \\
\hline PNB & Millones de dólares & $165,769.00$ & $221,533.00$ & $88,372.00$ & $98,195.00$ \\
\hline PNB per cápita & Dólares & $2,740.00$ & $1,110.00$ & $1,200.00$ & $4,350.00$ \\
\hline PNB per cápita & Dólares internacional PPP & $6,490.00$ & $3,390.00$ & $3,670.00$ & $7,730.00$ \\
\hline Crecimiento 1990-1997 & Porcentaje, promedio anual & 5.90 & 5.90 & 1.60 & 5.80 \\
\hline Agricultura en la economía & Participación en el PIB, \% & 11.00 & 16.00 & 19.00 & 12.00 \\
\hline Inflación 1990-1997 & Porcentaje, promedio anual & 4.80 & 8.60 & 8.60 & 4.50 \\
\hline Deuda externa 1997 & Millones de dólares & $93,416.00$ & $136,174.00$ & $45,443.00$ & $47,228.00$ \\
\hline Participación en el PIB & Porcentaje & 56.35 & 61.47 & 51.42 & 48.10 \\
\hline \multicolumn{6}{|l|}{ Apertura de la economía } \\
\hline Comercio como \% del PIB & Porcentaje, PPP & 29.70 & 13.70 & 30.80 & 90.00 \\
\hline
\end{tabular}

$\mathrm{PIB}=$ Producto Interno Bruto. $\mathrm{PPP}=$ Paridad del poder de compra. $\mathrm{PNB}=$ Producto Nacional Bruto.

Fuente: World Development Indicator, CD-Rom World Bank, 1999.

el Reino de Siam recuperó el dominio de sus asuntos financieros. Una década después, el papel central del estado tailandés se centraba en ejercer control sobre la tierra rural y en desarrollar la infraestructura básica de ferrocarriles, de electricidad y de agua. A finales de los treinta el estado incrementó su intervención en la economía y ya para 1945 unas treinta empresas públicas controlaban la producción de cigarros, papel, textiles, jabón y vidrio, entre otros.

La década de los cuarenta se caracterizó por la inestabilidad política. Durante los primeros tres años de la misma, los japoneses ocuparon Tailandia, entre 1944 y 1947 hubo cinco gobiernos y diez gabinetes y después del golpe de Estado de 1947, el régimen militar Pibul sufrió a su vez tres atentados de golpe de Estado entre 1948 y 1951.

En esas dos décadas el estado tailandés imprimió a su gobierno un carácter nacionalista con el fin de acotar la influencia de la minoría china en los asuntos económicos del país. Los chinos habían obtenido mucho éxito en la actividades del comercio y en el procesamiento y producción de hule, así como en la explotación del estaño y la extracción de la madera de teka, principales recursos del país.

La década de los cincuenta se caracterizó por el estrechamiento de las relaciones entre 
Cuadro 2

Tailandia y México: indicadores básicos

1997

\begin{tabular}{|c|c|c|c|}
\hline Variable & Unidad & Tailandia & México \\
\hline 1. Territorio & Miles $\mathrm{Km}^{2}$ & 510.9 & 1.908 .7 \\
\hline Forestal & Porcentaje (\%) & 23.0 & 29.0 \\
\hline Deforestación anual 1990-1995 & Porcentaje del total & 2.6 & 0.9 \\
\hline Recursos de agua & metros cúbicos per cápita & $2,954.0$ & $3,788.0$ \\
\hline 2. Población & Miles & $60,602.0$ & $94,349.0$ \\
\hline Crecimiento (1990-97) & Porcentaje (\%) & 1.2 & 1.8 \\
\hline Esperanza de vida al nacer & Años & 69.0 & 72.0 \\
\hline Tasa mortalidad infantil & Por 1000 nacidos vivos & 33.0 & 31.0 \\
\hline Mujer en la fuerza de trabajo & Porcentaje (\%) & 46.0 & 32.0 \\
\hline 3. Economía & & & \\
\hline PNB & Millones de dólares & $165,759.0$ & $348,627.0$ \\
\hline México/Tailandia & Veces & & 2.1 \\
\hline PNB per cápita & Dólares & $2,740.0$ & $3,700.0$ \\
\hline PNB per cápita & Dólares internacionales & $6,490.0$ & $8,110.0$ \\
\hline Crecimiento promedio anual (1990-97) & Porcentaje (\%) & 5.9 & 0.2 \\
\hline México/Tailandia & Veces & & 1.2 \\
\hline Agricultura en la economía & Porcentaje del PIB (\%) & 11.0 & 5.0 \\
\hline Inversión en la economía & Porcentaje del PIB (\%) & 35.0 & 26.0 \\
\hline Inversión del sector privado en el total & Porcentaje (\%) & 67.7 & 81.5 \\
\hline Inflación promedio anual 1990-97 & Porcentaje (\%) & 4.8 & 19.3 \\
\hline Gastos militares como porcentaje del PNB 1995 & Porcentaje (\%) & 2.5 & 1.0 \\
\hline 4. Sector externo & & & \\
\hline Exportaciones & Millones de dólares & $58,329.0$ & $110,431.0$ \\
\hline Exportaciones manufactureras como \% del total & Porcentaje (\%) & 71.0 & 81.0 \\
\hline $\begin{array}{l}\text { Importaciones } \\
\text { Comercio de bienes y servicios como \% del PIB }\end{array}$ & Millones de dólares & $63,181.0$ & $109,808.0$ \\
\hline medido en PPP & Porcentaje (\%) & 29.7 & 29.3 \\
\hline Balanza en cuenta corriente \% del PIB & Porcentaje (\%) & -2.0 & -1.8 \\
\hline Inversión extranjera directa como \% del PIB & Porcentaje (\%) & 2.4 & 3.1 \\
\hline Ingresos por turismo & Millones de dólares & $8,700.0$ & $7,593.0$ \\
\hline Visitantes & Miles & $7,263.0$ & $19,351.0$ \\
\hline Deuda externa total 1997 & Millones de dólares & $93,416.0$ & $149,690.0$ \\
\hline Como porcentaje del PNB & Porcentaje (\%) & $56 \%$ & $43 \%$ \\
\hline 5. Otros indicadores & & & \\
\hline Consumo de electricidad per cápita & kwh & $1,289.0$ & $1,381.0$ \\
\hline Líneas telefónicas & Por 1000 personas & 80.0 & 96.0 \\
\hline Computadoras personales & Por 1000 personas & 19.8 & 37.0 \\
\hline Carreteras pavimentadas como \% del total & Porcentaje del total (\%) & 97.5 & 37.4 \\
\hline
\end{tabular}

$\mathrm{PPP}=$ Paridad del poder de compra. $\mathrm{PIB}=$ Producto Interno Bruto. $\mathrm{PNB}=$ Producto Nacional Bruto.

Fuente: World Bank, World Bank Atlas 1999. 
Tailandia y Estados Unidos, con el afán de este último por frenar el avance del comunismo en la zona. Con la ayuda norteamericana se impulsaron programas de eliminación de la malaria, que constituyó un gran paso en materia de salubridad; se estableció un programa de mejoramiento del arroz con el que se avanzó parcialmente en el aumento en la productividad agrícola y se incrementó la superficie irrigada de 1 millón de hectáreas en 1947 a 1.6 millones en 1960. La internacionalización del país se vio impulsada por la Misión Norteamericana de Operaciones (USOM, por su sigla en inglés) y por la participación de Tailandia en el Fondo Monetario Internacional y el Banco Mundial en 1949.

Durante los cincuenta se fortalecieron las empresas públicas. Destaca la más grande de ellas, la Corporación de Desarrollo Económico Nacional NEDCO (por su sigla en inglés), con cinco subsidiarias que controlaban el sector azucarero, el del yute, el del mármol y el del papel. En esta década se inició también el control sobre los precios del arroz y se estableció un impuesto a su exportación. Estas dos medidas jugarían un papel importante en el desarrollo futuro del país. En primer lugar, los bajos precios del arroz mantuvieron deprimidos los ingresos de los agricultores mientras favorecían el ingreso real del trabajador urbano y, en segundo lugar, la extracción del excedente agrícola vía el impuesto a la exportación permitió financiar el desarrollo industrial. Este último se vio favorecido por una política de sustitución de importaciones (SI), que utilizó las tarifas más altas tanto con fines proteccionistas como también fuente generadora de ingresos para el gobierno. Mientras tanto al sector agrícola se le relegaba del proceso de crecimiento económico.
La modernización de la economía

Con el régimen de Marshal Sarit Thanart, que subió al poder con un golpe de Estado en 1958, se considera que Tailandia comenzó su etapa de desarrollo económico moderno. El régimen de Sarit repudió al estado "etnocentrista" e inició la planificación del desarrollo del país. Durante los sesenta la economía creció a una tasa promedio anual de 8.2 por ciento, estimulada por un ambiente internacional favorable. La guerra de Vietnam canalizó mayor ayuda internacional, ya que se consideraba a Tailandia como una base para sus operaciones. En esta etapa empezaron a establecerse algunas compañías transnacionales en el Reino de Siam.

La agricultura era la actividad predominante en esa época: participaba con 40 por ciento del PIB y empleaba a 82 por ciento de la fuerza de trabajo del país (cuadro 3); en tanto, el sector industrial representaba un poco menos de la quinta parte de la producción y la manufactura, 13 por ciento de la misma, lo cual denota el mínimo avance industrial del país en ese período. En contraste, en México, que había iniciado su etapa de crecimiento económico moderno en 1935, en la década de los sesenta el sector agropecuario contribuía con 15 por ciento del PIB y la industria, con 26 por ciento.

Durante los sesenta se terminó la red de escuelas primarias a nivel nacional y con ella se uniformó la enseñanza en el idioma tailandés, procurando con ello generar mayor lealtad al gobierno central y detener el comunismo, sobre todo en las provincias alejadas del noreste, norte y sur. También se implementó la red de administración de las aldeas, que permitía al gobierno central ejercer un mayor control sobre 


\section{Tailandia: evolución de la economía}

\begin{tabular}{|c|c|c|c|c|c|}
\hline & Unidad & $1960-1969$ & $1970-1979$ & $1980-1989$ & 1990-1999 \\
\hline \multicolumn{6}{|l|}{ Crecimiento del PIB } \\
\hline Crecimiento anual promedio & Porcentaje & 8.2 & 7.2 & 6.8 & 5 \\
\hline PIB per cápita & Año inicial del período & & & & \\
\hline PIB per cápita & Dólares & n.d. & 510 & 670 & 1840 \\
\hline Estructura del PIB & Porcentaje, año inicial del período & 100 & 100 & 100 & 100 \\
\hline Agricultura & & 39.7 & 30 & 23.2 & 14.4 \\
\hline Minería & & 1.1 & 1.5 & 3.4 & 2.7 \\
\hline Industria & & 17.6 & 24.4 & 27.6 & 32.9 \\
\hline Manufactura & & 12.6 & 17.1 & 21.3 & 24.7 \\
\hline Construcción & & 4.6 & 5.8 & 5.3 & 5.2 \\
\hline Electricidad y agua & & 0.4 & 1.5 & 1 & 3 \\
\hline Servicios & & 41.6 & 44.1 & 45.8 & 50 \\
\hline Composición del empleo & Porcentaje, año inicial del período & 100 & 100 & 100 & 100 \\
\hline Agricultura & & 82.3 & 79.3 & 71.9 & 63.5 \\
\hline Industria & & 4.2 & 5.8 & 7.9 & 14.2 \\
\hline Servicios & & 13.5 & 14.9 & 20.2 & 22.3 \\
\hline Distribución del ingreso & & & & & \\
\hline $20 \%$ mayor ingreso/20\% menor ingreso & Número de veces, inicio período & n.d. & 7.6 & 9.5 & 13.7 \\
\hline Crecimiento de las exportaciones & & & & & \\
\hline Crecimiento anual promedio & Porcentaje & n.d. & 10.7 & 14.8 & \\
\hline Composición de las exportaciones & Porcentaje, año inicial del período & & 100 & 100 & 100 \\
\hline Agricultura, pesca y silvicultura & & n.d. & 77.1 & 68.3 & 23.5 \\
\hline Minería & & n.d. & 0.1 & 2.1 & 1.4 \\
\hline Manufactura & & n.d. & 15.4 & 26.8 & 73.8 \\
\hline Otros & & n.d. & 7.4 & 2.8 & 1.3 \\
\hline Composición de las importaciones & Porcentaje, año inicial del período & 100 & 100 & 100 & 100 \\
\hline Bienes de consumo & & 35 & 19.4 & 10.2 & 8.5 \\
\hline Combustibles & & 10.6 & 8.6 & 31.1 & 9.2 \\
\hline Bines intermedios & & 18.1 & 24.9 & 24 & 33.8 \\
\hline Bienes de capital & & 24.6 & 34.7 & 24.4 & 38.8 \\
\hline Otros & & 11.7 & 12.4 & 10.3 & 9.7 \\
\hline Principales proveedores & Porcentaje, año inicial del período & 100 & 100 & 100 & 100 \\
\hline Estados Unidos & & 16.7 & 15 & 14.4 & 10.9 \\
\hline Unión Europea & & 24.8 & 18 & 19.3 & 13.7 \\
\hline Asia Pacífico & & 45.2 & 43 & 38.2 & 52 \\
\hline Japón & & 25.6 & 37 & 21.2 & 30.1 \\
\hline NIC & & 14.6 & 4 & 11.5 & 17.1 \\
\hline Asean- $5^{*}$ & & 5 & 2 & 5.5 & 4.8 \\
\hline Asean Socialista* & & 1.1 & 2.4 & 4.6 & 4.1 \\
\hline Otros & & 13.3 & 24 & 28.1 & 23.4 \\
\hline Principales mercados & Porcentaje, año inicial del período & 100 & 100 & 100 & 100 \\
\hline Estados Unidos & & 13.9 & 13 & 12.6 & 26.2 \\
\hline Unión Europea & & 14.6 & 17 & 22.2 & 21.5 \\
\hline Asia Pacífico & & 60.1 & 60.8 & 41.9 & 38.4 \\
\hline Japón & & 17.8 & 26 & 15.1 & 17.2 \\
\hline NICS* & & 20.9 & 18 & 14.9 & 15.1 \\
\hline Asean- $5^{\star}$ & & 21.2 & 8 & 8.6 & 4.3 \\
\hline Asean Socialista* & & 0.2 & 8.8 & 3.3 & 1.8 \\
\hline Otros & & 11.4 & 9.2 & 23.3 & 13.9 \\
\hline Grado de apertura & $\begin{array}{l}\text { (Exportaciones+importaciones)/PIB } \\
\text { Porcentaje }\end{array}$ & n.d. & 37.1 & 54.7 & 76.7 \\
\hline
\end{tabular}

* NIC=Nuevos países industrializados: Taiwán, Corea del Sur, Hong Kong (China) y Singapur: Asean 5: Filipinas, Indonesia, Malasia, Tailandia y Brunei. Asean Socialista: Camboya, China, Laos, Myanmar y Vietnam.

Fuente: Dixon, Chris, The Tahi Economy. Uneven development and internationalisation, Routledge, London, 1999, varios cuadros: pp. 3, 4; 5; 6; 7; 8; 9; 10; 11; 16 y 218; STAT-USA, Country Commercial Guide for Thailand, Appendix B; Institute of Developing Economies \& Jetro, 1999 Economic Outlook for East Asia; FMI, International Financial Statistics. 
los jefes electos de las mismas e incorporarlos fácilmente a la burocracia estatal.

Aunque se llevaron a cabo proyectos de apoyo al campo, sobre todo en irrigación, electricidad y caminos, éste siguió relegado en contraste con el alto apoyo brindado a la manufactura (con exensión de impuestos hasta por ocho años y garantías de no nacionalización). Más aún, el impuesto a las exportaciones de arroz contribuía a mantener bajo el precio del cereal y garantizaba salarios bajos.

En la década de los setenta la estructura productiva del país presentó algunos cambios importantes. El sector industrial aumentó su participación a 24 por ciento del PIB, sin embargo no generaba el suficiente empleo y la mano de obra tailandesa permanecía en el sector rural, prácticamente en iguales términos relativos que en la década anterior. Dos factores explican el comportamiento anterior. Por un lado, el aumento en la producción agrícola en Tailandia se ha debido a la incorporación de nuevas tierras más que al aumento en la productividad. Así, la población rural encontró un medio para mantener sus ingresos en la expansión de la frontera agrícola, a costa de la riqueza forestal del país. Por otro lado, la política de estimular la producción industrial subsidiando las importaciones de capital volvió intensivas a las actividades industriales en el uso del capital e incapaces de absorber la mano de obra disponible.

No obstante, el sector agrícola en los sesenta comenzó a mostrar una mayor diversificación en los agronegocios, pasando de la producción de azúcar, maíz, yute y cassava a producción de alimentos procesados para animales, semillas, carne de cerdo y pollo, enlatado de frutas y productos marinos. Así, el sector exportador tailandés continuó siendo altamente dependiente de las exportaciones agrícolas (77 por ciento), vulnerables a las variaciones de los precios internacionales en este tipo de productos y a las variaciones en la producción sujeta a factores ambientales.

Durante los setenta Tailandia experimentó dos choques externos desfavorables. Por un lado, sufrió el impacto negativo del incremento de los precios del petróleo dada su fuerte dependencia de las importaciones del energético; para reducir el efecto sobre el consumo el gobierno subsidió los precios de los combustibles, retrasando con ello el ajuste en su uso. Por otro, Estados Unidos retiró sus bases militares con el consiguiente efecto adverso de la reducción del gasto norteamericano en su territorio, sobre todo en la región del noreste.

Internamente, el país estuvo sujeto a inestabilidad política por los cambios de gobierno en 1973, 1976 y 1977, al mismo tiempo que la desigualdad en el desarrollo regional y en la distribución del ingreso se presentaban como dos problemas estructurales no resueltos por el crecimiento sostenido de 7.2 por ciento anual durante esta etapa.

\section{Los ochenta: de la sustitución de importaciones a la liberalización}

En la década de los ochenta Tailandia continuó con un patrón de crecimiento sostenido de 6.8 por ciento promedio anual (cuadro 3). El ingreso per cápita se había incrementado en 30 por ciento, al pasar de 570 dólares en los setenta a 670 dólares en los ochenta. El sector industrial representó en este período cerca de 28 por ciento del PIB y la manufactura había casi duplicado su contribución, comparada a los sesenta. Sin embargo, el empleo en el sector siguió siendo bajo y la agricultura continuaba absorbiendo 72 por ciento de la fuerza de trabajo, denotando una baja productividad, pues su contribución a la producción era de 23 por ciento.

En este período las exportaciones experimentaron un fuerte crecimiento de 14.8 por ciento anual, superior al de la década anterior de 10 por ciento (cuadro 3); esto a pesar de los elevados niveles de protección prevalecientes todavía en la economía. Aunque la dependencia de las exportaciones primarias siguió siendo alta (68 por ciento), las exportaciones manufactureras representaban ya 27 por ciento de los ingresos por ventas al exterior y comenzaron a mostrar una mayor diversificación: incremento de alimentos 
procesados, de vestido, de productos elaborados de piel y de productos eléctricos. La producción comenzó a ser más dependiente de las exportaciones: del PIB alimenticio se exportaba 21 por ciento; del de productos eléctricos, 33 por ciento y del textil 10 por ciento.

No obstante, todavía en la primera mitad de los ochenta Tailandia continuaba siendo un país rural, con un crecimiento basado en la sustitución de importaciones y en el sector agrícola, hasta mediados de los ochenta, cuando esta política empezó a modificarse. A partir de 1986 se redujeron los subsidios a los productos petroleros y en 1988 se suprimió finalmente el impuesto a las exportaciones de arroz. Los aranceles comenzaron a disminuir en 1990 y desde de ese año se aplicó un programa de privatización y de desregulación de los mercados financieros, al tiempo que se introdujo una reforma impositiva. Comparado a otros países, Tailandia siguió un patrón de ajuste "extremadamente gradual".

\section{Los noventa: del auge económico a la crisis}

El auge experimentado por la economía en los primeros seis años de la década de los noventa, durante el cual el país creció a tasas promedio de 8.5 por ciento anual, estuvo impulsado sobre todo por el sector exportador. La entrada de divisas al país se vio también favorecida por las remesas de los trabajadores tailandeses en el exterior, en Medio Oriente, y por las entradas provenientes del turismo.

También contribuyó al auge de los noventa, la llegada de mayor inversión extranjera, en especial la procedente de los vecinos en Asia Pacífico y orientada principalmente al mercado exterior. Esta ola de inversión se vio favorecida por varios factores: a) la revaluación del yen en el Acuerdo Plaza, que hizo perder competitividad a las exportaciones japonesas y el capital nipón buscó nuevas bases de producción en países con menores costos que el suyo; b) una menor atracción para invertir en los otros países del ASEAN-4: en Filipinas por la crisis económica, en Malasia por la inestabilidad política y en Indonesia por mayores controles a la inversión; c) para los NIC y Japón, los países del sudeste asiático constituían nuevas bases para entrar a los mercados protegidos de Estados Unidos y la Unión Europea, más abiertos a los países menos desarrollados del sudeste asiático; d) las laxas regulaciones sobre el medio ambiente prevalecientes en Tailandia fueron un atractivo para Corea del Sur, Taiwán y Japón; e) Tailandia ofrece ahora mayor atractivo para la inversión en industrias intensivas en mano de obra, convirtiéndose en el mayor ensamblador de disk drives.

Por todos los factores anteriores, las compañías transnacionales ven en Tailandia una oportunidad y la puerta de entrada a las economías vecinas que están creciendo, como Vietnam, Laos, Myanmar y Camboya. Para empresas como Unilever, P\&G, Nestlé, Toyota y Matsuhita, Tailandia se ha convertido en la base productiva de los sectores textiles, electrónicos y autopartes, para servir a sus redes regionales. El mercado regional es el objetivo de estas empresas. ${ }^{2}$

Así, las exportaciones se han diversificado y las del sector textil han dado paso a las del electrónico; las de productos alimentarios representan 10 por ciento del total. Para 1997, 71 por ciento de las exportaciones tailandesas estaban constituidas por manufacturas (cuadro 2). No obstante, las exportaciones siguen siendo altamente dependientes de las importaciones, esto es, existe una baja vinculación con el sector de pequeñas y medianas empresas del país.

En los noventa el ingreso per cápita de los tailandeses se duplicó con respecto a la década anterior. El sector industrial representa ya 33 por ciento de la producción nacional, mientras que el agrícola ha disminuido su participación a 14 por ciento, pero sigue empleando a 60 por ciento de la mano de obra del país. Es decir, el problema de una baja productividad agrícola no ha sido resuelto y la distribución del ingreso ha tendido a empeorar: 20 por ciento de las familias de mayores recursos poseen un ingreso trece veces superior a 20 por ciento de familias de más 
bajos ingresos (cuadro 3). Los expertos agrícolas indican que para aumentar al doble la productividad en el cultivo del arroz es necesario emplear semillas mejoradas e incrementar la irrigación, ya que sólo 20 por ciento de la superficie agrícola está irrigada. Los especialistas indican también que deben mejorar los deficientes sistemas de distribución para frutas y vegetales frescos e incrementar la inversión en tecnologías de almacenaje y empaque, en investigación de semillas mejoradas, al tiempo que los agricultores tengan un mayor acceso a la información y al crédito. ${ }^{3}$

El sector financiero tailandés fue el que empezó a mostrar los problemas más serios a mediados de los noventa. Para 1996 la deuda privada externa se incrementó. Para 1997 la deuda externa alcanzó un nivel de 93 mil millones de dólares, que representaba 56 por ciento del PIB. Un sector financiero con regulaciones muy laxas propició los movimientos volátiles de capital, y produjo una burbuja en los precios de los sectores financieros y de bienes raíces. La crisis de balanza de pagos hizo necesaria la devaluación del baht en 1997. A partir de ahí la economía mostró tasas negativas de crecimiento en los tres años siguientes: de 0.4 por ciento en 1997 , de 8 por ciento en 1998 y de -0.2 por ciento en 1999. Esta crisis ha sacado a flote los problemas estructurales que todavía enfrenta la economía de Tailandia.

\section{Problemas estructurales}

El modelo de desarrollo adoptado por Tailandia se basó en una explotación extensiva de sus recursos naturales y en un modelo de sustitución de importaciones, durante tres décadas hasta los ochenta, y desde entonces en una estrategia de menor intervención del Estado en la economía y de apoyo a las exportaciones y a la inversión extranjera, fomentó el crecimiento económico del país, pero también se fueron dejando a un lado problemas estructurales que con la crisis de 1997 se han exacerbado.

La falta de infraestructura física adecuada se ha convertido en un cuello de botella para la producción y el comercio interno y externo.
Bangkok es la única ciudad de su tamaño en Asia que carece de transporte masivo. Las instalaciones portuarias son insuficientes para mover los flujos de bienes del país. Por otra parte, las regulaciones tan laxas sobre contaminación están imponiendo límites al crecimiento industrial y han desalentado el turismo.

La fuerte concentración industrial en el área metropolitana de Bangkok ha incrementado los precios de la tierra y el crecimiento de la industria ha elevado los costos de la mano de obra. Los sectores intensivos en mano de obra han perdido competitividad; mientras la falta de mano de obra calificada está limitando la movilidad a otros sectores de mayor valor agregado y mayores ingresos. A diferencia de los NIC (que cuentan con una mano de obra educada y altamente calificada), en Tailandia la escasez de recursos humanos calificados se ha convertido en uno de los mayores problemas que está frenando su avance e impidiendo la movilidad social; a tal punto que en el último Plan Nacional de Desarrollo es prioridad el objetivo de desarrollo de recursos humanos.

La desigual distribución del ingreso está limitando el tamaño del mercado, además de que constituye una amenaza para la estabilidad social del país. La población más pobre se encuentra en el campo. Sin embargo, la frontera agrícola ya se ha agotado, la deforestación y la consecuente erosión de las tierras está poniendo un límite. Ello implica que los aumentos en la producción agrícola deberán basarse en programas para elevar la productividad más que en el incremento de la superficie cosechada. El sector agrícola reclama la atención que le fue negada durante las últimas cuatro décadas, cuando en aras del desarrollo industrial se le impuso una pesada carga y se relegó a segundo plano el impulso a su crecimiento.

Como mencionaba el primer ministro tailandés, Chuan, refiriéndose a la crisis que ha enfrentado Tailandia en los últimos años: "Si comparamos el estado de la economía de Tailandia con el funcionamiento del cuerpo humano, nos hemos recuperado de la 
enfermedad, pero todavía no estamos tan fuertes como lo fuimos en el pasado". 4

\section{Fuentes:}

Dixon, Chris. The Thai Economy. Uneven development and interantionalisation. Routledge, London 1999, Caps. 2-4 y 8; Hewison, Kevin, "Emerging social forces in Thailand: new political and economic roles" en Robison, Richard and Goodman, David S. G., The New Rich in Asia. Mobile phones, McKonald's and middle-class revolution. PP. 79105; Visudtibhan, Kanoknar y Yip, George, "ThailandTiger by the Tail? en Yip, George, Asian Advantage. Key Strategies for Winning in the Asia-Pacific Region, Perseus Books, Massachusetts, 1999, PP. 203-218. y Far Eastern Economic Review, varios números.

\section{Notas}

1 La mayor parte de esta sección se basa en Dixon, Chris, The Thai Economy. Uneven development and internationalisation, Routledge, London, 1999, caps. 14 y el 8.

2 Véase Visudtibhan, Kanoknar y Yip, George, "ThailandTiger by the Tail? en Yip, George, Asian Advantage. Key Strategies for Winning in the Asia-Pacific Region, Perseus Books, Massachusetts, 1999, pp. 203-218.

3 Véase Crispin, Shawn y Goad, Pierre, "Thai Cornucopia" en Far Eastern Economic Review, July 13, 2000, pp 58-59.

4 Citado en Crispin, Shawn y Vatidiotis, Michael, "A Moment of Truth for Democracy" en Far Eastern Economic Review, November 9, 2000, p. 15. 